\title{
Austerity and Its Impact upon Public Services in the UK: An Analytic Narrative Approach.
}

\author{
Tania Arrieta Hernandez \\ University of Leicester, UK
}

\begin{abstract}
This paper explores the social consequences of the austerity programme in the UK. The analysis was conducted through an analytic narrative approach, where three narratives were studied to understand the changing landscape of public service provision during the austerity programme. The first story shows that budgetary reductions marginalised communities and led to the social exclusion of vulnerable groups. Some social problems have been reinforced such as homelessness, children in need receiving less support from the state and a rising inequality in the provision of public services. The second narrative shows that the reduction of public service provision has not been mitigated by a higher participation of communities and different providers (e.g., voluntary and private providers). These groups have encountered difficulties in increasing their participation in public service provision. The third narrative reflects on the retreat of public trade unions and how this retreat has affected different public services. Trade unions' retreat should not be thought as a voluntary retreat but as a retreat imposed by the governments in power since 2010. The analysis shows that the changing landscape of the public sector is influenced by these three narratives that at times seem to differ but that in reality overlap one another to reflect the retrenchment of the public sector in service provision. The analysis concludes that are the less positive stories such as those of marginalisation and the transfer of responsibility from the government to communities in service provision that have been more pronounced in recent years.
\end{abstract}

Keywords: development; erosion; exclusion; inequality; vulnerable communities. 